Case report

\title{
Reticulum cell sarcoma in azathioprine-treated systemic lupus erythematosus
}

\author{
M. E. HEHIR, J. R. SEWELL, AND G. R. V. HUGHES \\ From the Royal Postgraduate Medical School, London
}

SUMMARY The development of a reticulum cell sarcoma in the lung of a patient with systemfic lupus erythematosus treated with azathioprine for 18 months is described. This possible hazard gf immunosuppressive therapy is discussed in relation to patients with SLE.

Tumour induction is recognised as a potential hazard of immunosuppressive therapy, and a high incidence of reticulum cell sarcoma has been observed in renal transplant recipients treated with azathioprine (Hoover and Fraumeni, 1973). By contrast, only 2 cases of reticulum cell sarcoma developing in patients with systemic lupus erythematosus (SLE) treated with azathioprine have been reported (Goldenberg et al., 1971; Lipsmeyer, 1972) despite the widespread use of this agent over the last decade. We report here a third case and discuss the possible implications of this association.

\section{Case report}

A 43-year-old housewife with a 15-year history of SLE was admitted to the Hammersmith Hospital in November 1976, for investigation of a well delineated left upper lobe shadow (Fig. 1), which had increased in size over the previous 2 months. Needle biopsy of the lesion was non-diagnostic but necrotic material was aspirated, and thoracotomy was performed, at which a large, hard mass in the apical segment of the left lower lobe was resected. Histology was that of a reticulum cell sarcoma (Professor J. G. Azzopardi). The patient made an uncomplicated recovery, and on clinical and radiological assessment 1 year after presentation there was no evidence of recurrence. Eighteen months before her admission to hospital on this occasion azathioprine $150 \mathrm{mg}$ daily $(2.25 \mathrm{mg} / \mathrm{kg} /$ day $)$ had been added to her steroid regimen in an attempt to reduce her steroid requirement. The initial diagnosis of SLE was made

Accepted for publication 15 March 1978

Correspondence to $\mathrm{Dr}$ G. R. V. Hughes, Hammersmith Hospital, Ducane Road, London W12 OHS. in 1962 , when she presented with polyarthralgê, alopecia, Raynaud's phenomenon, and photosensitive rash, and was found to have LE cells. Subsequent DNA-binding values (Farr test) of $90 \%$ and $92 \%$ (normal range-below $30 \%$ ) substantiated the diagnosis of SLE. The patient had been maintained on prednisone in doses ranging from 10 to $\mathrm{mg}$ per day from the time of diagnosis, because of severe recurrent vasculitis. Azathioprine was witi drawn 1 month prior to admission to the Hammersmith Hospital because of lack of benefit.

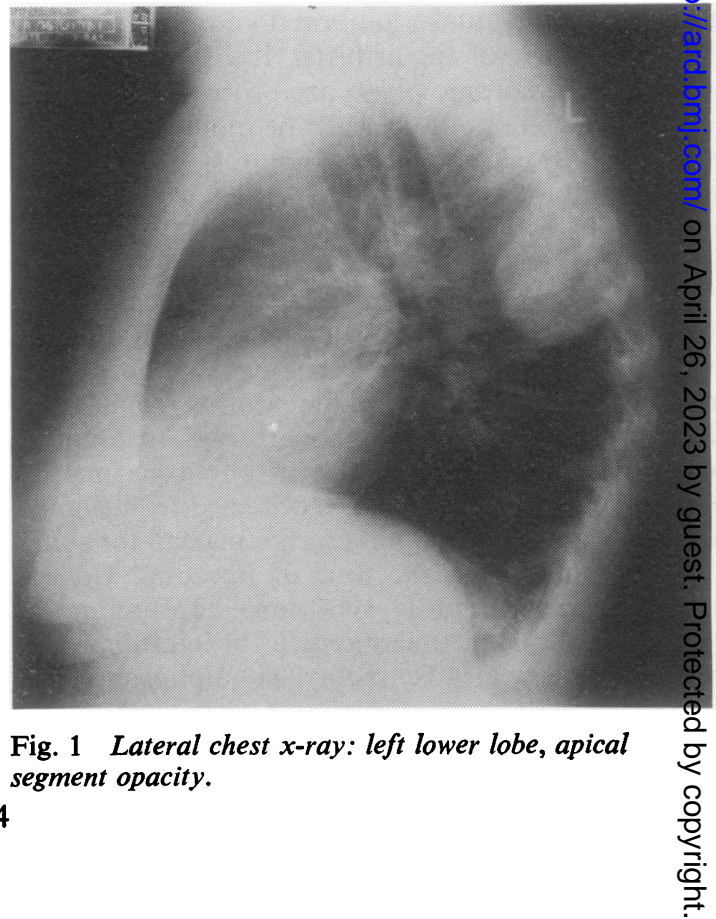




\section{Discussion}

The striking incidence of early lymphoreticular malignancies in renal treatment patients receiving immunosuppressive agents has not been mirrored in other patients receiving these drugs. This therapy might be expected to carry a particular risk of reticuloendothelial system malignancy in SLE with its altered immune status. In the New Zealand B/W $F_{1}$ hybrid mouse, the close disease model of SLE, the administration of azathioprine resulted in a marked increase in lymphoma frequency (Casey, 1973). To date only 2 patients with SLE receiving azathioprine developing reticulum cell sarcoma have been reported (Goldenberg, 1971; Lipsmeyer, 1972).

The author of the first report of a reticulum cell sarcoma developing in a patient with SLE treated with azathioprine urged that the occurrence of any similar cases should be reported and that a registry be maintained for recording malignancies in patients with rheumatic and 'autoimmune' diseases, whether or not they had been given immunosuppressive drugs (Lipsmeyer, 1972). Reporting of isolated cases would not establish the risk or otherwise of immunosuppressive therapy, and we therefore agree that units using these agents keep registers of all patients in the disease categories for which these are employed, so that adequate data are available to a central registry such as that at Oxford (DHSS Cancer Epidemiology and Clinical Trials Unit, Department of the Regias Professor of Medicine, University of Oxford, 9 Keble Road, Oxford).

AdDendum. The patient died suddenly on 5 June, 1978 and at her necropsy was found to have pulmonary embolisation. Also apparent was a soft yellowish white mass behind the left 3rd, 4th, and 5th ribs adjacent to the spine and invading adjacent lung tissue. Histological examination of this showed that her reticulum cell sarcoma had recurred.

\section{References}

Casey, T. P. (1973). Azathioprine administration to NZB $\times$ NZW hybrid mice with lupus nephritis: beneficial effects complicated by malignant lymphoma. New England Medical Journal, 78, 290-295.

Goldenberg, G. J., Paraskevas, F., and Israels, L. G. (1971). Lymphocyte and plasma cell neoplasms associated with autoimmune diseases. Seminars in Arthritis and Rheumatism, 1, 174-188.

Hoover, R., and Fraumani, J. F. (1973). Risk of cancer in renal-transplant recipients. Lancet, $2,55-57$.

Lipsmeyer, E. A. (1972). Development of malignant lymphoma in a patient with systemic lupus erythematosus treated with immunosuppression. Arthritis and Rheumatism, 15, 183-186. 